\title{
HUBUNGAN ANTARA KADAR Pb DALAM DARAH DENGAN KEJADIAN HIPERTENSI PADA OPERATOR SPBU DI KOTA YOGYAKARTA
}

\author{
Hesti Rosyidah, Sitti Nur Djannah \\ Fakultas Kesehatan Masyarakat, Universitas Ahmad dahlan, Yogyakarta
}

\begin{abstract}
Background: The spread of $\mathrm{Pb}$ to humans could cause many negative effects to health such as cardiovasculer system, hypertension and carsinogenic. The change of society pattern from agrarian to industry and life style, community social economic became was one of the things that cause the increasing of un infected prevalence, that was hypertension. The average of hypertension prevalence in Indonesia around 8,3 percent. Low concentrate of $\mathrm{Pb}$ inside blood (3-5 $\mu \mathrm{g} / \mathrm{dl})$ had cause effect to blood pressure and $\mathrm{Pb}$ also took act in hypertension patolgy. The air pollution in Yogyakarta city alraedy reach the normal standar of air quallity. One of the area with high air pollution was Public Refueling Station (SPBU). The operator employee has high risk to conteminate by dangerous chemical substances especially plumbum by gasoline and motor vehicle gas emission that waiting queue refuelingor vehivle that depart after refueling. The purpose of this study was to determine the relationship of $\mathrm{Pb}$ concentrate inside blood with hypertension incident to SPBU operator in Yogyakarta city.

Method : This was observational analytic using cross sectional approach with quantitative method. Sample of this study was operator in four SPBU Yogyakarta city amount 25 people. To analyzed $\mathrm{Pb}$ concentrate inside blood used spectrophotometry with AAS method, the measuring of blood pressure used mercury sphygmomanometer and respondent characteristic used interview orientation. Data analysis used univariate and bivariate.

Result : There was significant relationship between $\mathrm{Pb}$ concentrate in blood with hypertension incident to SPBU operator Yogyakarta city with signicancy value $(p)$ amount $0,028 p=0,028<\alpha=0,05$, the risk seen by $\mathrm{RR}$ value $=2,619(95 \% \mathrm{Cl}: 0,944-7,625)$; so Ho which mention there was no relationship between $\mathrm{Pb}$ concentrate inside blood with hypertension incident to SPBU operator "rejected". Ha which mention there was relationship between $\mathrm{Pb}$ concentrate inside blood with hypertension incident to SPBU operator "accepted".

Conclusion : $\mathrm{Pb}$ concentrate inside blood had significant relationship with hypertension incident to SPBU operator Yogyakarta city.
\end{abstract}

Keywords : Plumbum $(\mathrm{Pb})$, Hypertension, Public Refueling Station operator

\section{PENDAHULUAN}

Perkembangan dan kemajuan dibidang transportasi tampak dengan semakin tingginya jumlah dan jenis kendaraan yang melintasi ruas jalan perkotaan. Kepadatan arus lalu lintas disebabkan oleh tingginya volume kendaraan yang tidak sesuai dengan ketersediaan ruas jalan yang ada. Dampak negatif yang didapatkan adalah tingginya tingkat polusi udara lingkungan kota, sebagai hasil emisi gas pembuangan kendaraan bermotor. Dilihat dari sumbernya, pencemaran udara terbesar memang berasal dari asap buangan kendaraan bermotor. Adapun unsur yang terdapat dari hasil emisi gas buangan yang berbahaya diantaranya adalah unsur $\mathrm{Pb}$. Unsur $\mathrm{Pb}$ ini sendiri sebenarnya sudah ada di dalam bahan bakar bensin. Oleh karena mesin kendaraan tidak sempurna dalam proses pembuangannya, maka unsur $\mathrm{Pb}$ menjadi unsur yang terlepas bebas di udara. ${ }^{1}$ 
Kendaraan bermotor mengeluarkan zat-zat berbahaya yang dapat menimbulkan dampak negatif, baik terhadap kesehatan manusia maupun terhadap lingkungan. Pajanan timbal pada manusia dapat menimbulkan berbagai efek negatif pada kesehatan, yaitu pada saraf pusat dan saraf tepi, sistem kardiovaskuler, sistem hematopoetik, hipertensi, ginjal, pencernaan, sistem reproduksi, dan bersifat karsinogenik. $^{2}$

Hipertensi sering disebut the silent killer dan bersifat heterogenous group of disease karena dapat menyerang siapa saja dari berbagai kelompok sosial ekonomi. Hipertensi menimbulkan angka morbiditas (kesakitan) dan mortalitas (kematian) yang tinggi. Menurut penyebabnya hipertensi dikelompokkan menjadi 2 macam yaitu hipertensi esensial atau primer yang tidak diketahui sebab-sebabnya, serta hipertensi renal atau sekunder yang diketahui sebabnya seperti penyakit ginjal, gangguan hormon, diabetes dan sebagainya. Hipertensi esensial mempunyai prevalensi 90 persen sedangkan hipertensi sekunder hanya 10 persen dari keseluruhan penyakit hipertensi yang ada. Untuk itu hepertensi esensial lebih utama untuk mendapatkan perhatian dalam upaya pencegahan dan pengobatannya, karena penderita hipertensi esensial pada umumnya tidak merasakan adanya gejala. ${ }^{3}$

Diperkirakan sekitar 80 persen kenaikan kasus hipertensi terjadi terutama di negara-negara berkembang di tahun 2025. Secara global World Health Organization (WHO) memperkirakan penyakit tidak menular menyebabkan sekitar 60 persen kematian dan 43 persen kesakitan di seluruh dunia. Rata-rata prevalensi hipertensi di Indonesia sekitar 8,3 persen, sedangkan prevalensi hipertensi di kota besar (Jakarta) lebih tinggi yaitu sekitar 14,2 persen dan 15 persen. ${ }^{4}$ Dari sejumlah 639 juta kasus di tahun 2000, diperkirakan menjadi 1,15 milyar kasus di tahun $2025 .^{5}$ Di Jawa Tengah prevalensi hipertensi pada tahun 2007 diketahui bahwa sekitar 4.000 orang dewasa mengalami hipertensi. Berikut prevalensi hipertensi di seluruh propinsi Indonesia.

Tabel 1. Sepuluh besar prevalensi hipertensi di Indonesia tahun 2007

\begin{tabular}{clc}
\hline No & Nama Propinsi & Prevalensi (\%) \\
\hline 1 & Jawa Timur & 37,4 \\
2 & Bangka Belitung & 37,2 \\
3 & Jawa Tengah & 37 \\
4 & Sulawesi Tengah & 36,6 \\
5 & D.I Yogyakarta & 35,8 \\
6 & Riau & 34 \\
7 & Sulawesi Barat & 33,9 \\
8 & Kalimantan Tengah & 33,6 \\
9 & Nusa Tenggara Barat & 32,4 \\
10 & Sulawesi Tenggara & 31,6 \\
\hline
\end{tabular}

Adapun faktor-faktor yang berperan dalam hipertensi adalah umur, suku, jenis kelamin, obesitas, stres, diabetes mellitus, alkohol, pil KB, konsumsi garam berlebih, dan unsur logam berbahaya $\left(\mathrm{Pb}\right.$, thalium, dan cadmium) dan sebagainya. ${ }^{6}$ Bahan aditif yang ditambahkan ke dalam bahan bakar kendaraan bermotor pada umumnya terdiri dari $62 \%$ tetraetil- $\mathrm{Pb}, 18 \%$ etilenklorida, $18 \%$ etilenbromida, dan $2 \%$ campuran bahan lain.

Efek paparan $\mathrm{Pb}$ terhadap tekanan darah lebih jelas ditunjukkan dengan paparan secara kronis dibanding paparan secara akut. Pada kadar $\mathrm{Pb}$ dalam darah relatif rendah (5-35 $\mu \mathrm{g} / \mathrm{dl}$ ) telah menimbulkan efek terhadap tekanan darah. ${ }^{7}$ Moller dan Kristensen menyatakan bahwa $\mathrm{Pb}$ berperan dalam patofisiologi hipertensi. Secara biokimiawi $\mathrm{Pb}$ mempengaruhi metabolisme kalsium (Ca) pada kontraksi otot pembuluh 
darah vaskuler dan system rennin-angiotensin. Data dari Samsat bahwa kendaraan bermotor di Yogyakarta berjumlah 437.243 unit menghabiskan BBM 139.904 liter perhari. Pemakaian sebanyak 139.904 liter BBM perhari yang teroksidasi dengan oksigen $\left(\mathrm{O}_{2}\right)$ akan mengeluarkan gas emisi 0,44 ppm $\mathrm{CO}_{2}, 37 \mathrm{ppm} \mathrm{CO}, 3,7 \mathrm{ppm}$ NOx, 2,8 ppm SOx, dan 6,7 ppm HC. ${ }^{8}$ Pencemaran udara di Kota Yogyakarta, berada di atas ambang normal standar baku mutu udara. Petugas SPBU memiliki risiko tinggi terpapar bahan kimia berbahaya khususnya timbal dari bensin dan emisi gas kendaraan bermotor yang sedang menunggu antrian pengisisan bahan bakar, ataupun kendaraan yang berangkat setelah mengisi bensin. ${ }^{9}$

Studi pendahuluan yang dilakukan tercatat 4 SPBU dengan jumlah petugas 86 orang. Rata-rata bekerja 7 jam sehari dan beberapa dari mereka merasa sering pusing, sakit kepala, mual dan sesak nafas pada saat bekerja. Tujuan penelitian ini adalah untuk mengetahui hubungan antara kadar $\mathrm{Pb}$ dalam darah dengan kejadian hipertensi pada operator SPBU di Kota Yogyakarta.

\section{METODE PENELITIAN}

Penelitian ini termasuk penelitian analitik dengan metode kuantitatif, dengan rancangan penelitian yang digunakan adalah pendekatan cross sectional, di lakukan di SPBU Gambiran, SPBU Bugisan dan SPBU Kyai Mojo untuk mencari dan mendapatkan informasi tentang pengaruh kadar $\mathrm{Pb}$ dalam darah petugas operator dengan kejadian hipertensi di SPBU Gambiran, SPBU Bugisan dan SPBU Kyai Mojo. Penelitian ini dilaksanakan pada bulan Juni 2010.

Instrumen penelitian data primer dengan mengukur tekanan darah, mengambil sampel darah responden untuk diperiksa kadar $\mathrm{Pb}$ yang terkandung dalam darah, serta untuk memberikan penegasan terhadap hasil penelitian melalui lembar pedoman wawancara. Lembar pedoman wawancara digunakan untuk mengetahui masa kerja, riwayat penyakit, umur, dan kebiasaan (merokok dan konsumsi natrium) responden, dengan menggunakan formulir isian yang dibuat oleh peneliti untuk mengetahui karakteristik responden.

\section{HASIL PENELITIAN DAN PEMBAHASAN}

\section{a. Hasil Penelitian}

1) Deskripsi Lokasi Penelitian

Kota Yogyakarta adalah ibu kota Provisi Daerah Istimewa Yogyakarta (DIY) yang berada di tengah-tengah Propinsi DIY. Luas wilayah Kota Yogyakarta 32,5 $\mathrm{km}^{2}$. Secara geografis Kota Yogyakarta terletak antara $110^{\circ} 24^{\prime} 19^{\prime \prime}$ sampai $110^{\circ}$ $28^{\prime} 53^{\prime \prime}$ Bujur Timur dan $7^{\circ} 15^{\prime} 24^{\prime \prime}$ sampai $7^{\circ} 49^{\prime} 26^{\prime \prime}$ Lintang Selatan dengan ketinggian rata-rata $114 \mathrm{~m}$ diatas permukaan laut dengan batas wilayah sebagai berikut:

Sebelah utara : Kabupaten Sleman

Sebelah timur : Kabupaten Bantul \& Sleman

Sebelah selatan : Kabupaten Bantul

Sebelah barat : Kabupaten Bantul \& Sleman 
Kota Yogyakarta memiliki 17 SPBU diantaranya yaitu SPBU Bugisan, SPBU Kyai Mojo dan SPBU Gambiran, dengan jumlah petugas (Operator) sebanyak 71 orang. Responden ditentukan secara random.

Tabel 2. Lokasi SPBU dan jumlah operator SPBU di Kota Yogyakarta yang dijadikan responden tahun 2010

\begin{tabular}{llcc}
\hline No & Lokasi SPBU & Responden & Persentase (\%) \\
\hline 1 & Bugisan & 13 & 52 \\
\hline 2 & Gambiran & 6 & 24 \\
\hline 3 & Kyai Mojo & 6 & 24 \\
\hline & & 25 & 100 \\
\hline
\end{tabular}

2) Karakteristik Responden

Dalam penelitian ini jumlah responden sebesar 25 petugas operator diambil dari 4 SPBU di Kota Yogyakarta berdasarkan kriteria inklusi.

Tabel 3. Karakteristik responden berdasarkan umur operator SPBU di Kota Yogyakarta tahun 2010

\begin{tabular}{ccc}
\hline Umur & Frekuensi & Presentase (\%) \\
\hline $15-20$ & 1 & 4.0 \\
\hline $21-25$ & 2 & 8.0 \\
\hline $26-30$ & 7 & 28.0 \\
\hline $31-35$ & 2 & 8.0 \\
\hline $36-40$ & 3 & 12.0 \\
\hline $41-45$ & 2 & 8.0 \\
\hline $46-50$ & 1 & 4.0 \\
\hline $51-55$ & 5 & 20.0 \\
\hline $56-60$ & 2 & 8.0 \\
\hline Total & 25 & 100.0 \\
\hline
\end{tabular}

Pada tabel 3. di atas terlihat dari 25 responden yang diteliti, bahwa kebanyakan berada pada kelompok umur 26-30 tahun yaitu $7(28,0 \%)$, sedangkan paling sedikit berada pada kelompok umur 15-20 dan 46-50 tahun sebesar 1 (4,0 \%) responden.

3) Status hipertensi

Status hipertensi responden dapat dilihat pada tabel 4. berikut 
Tabel 4. Distribusi responden berdasarkan status hipertensi operator SPBU di Kota Yogyakrta tahun 2010

\begin{tabular}{ccc}
\hline Status hipertensi & Frekuensi & Presentasi (\%) \\
\hline Ya & 13 & 52.0 \\
\hline Tidak & 12 & 48.0 \\
\hline Total & 25 & 100.0 \\
\hline
\end{tabular}

Pada tabel 4. di atas menujukkan bahwa dari 25 responden yang diteliti kebanyakan menderita hipertensi yaitu sebesar 13 responden $(52,0 \%)$, sedangkan yang tidak menderita hipertensi sebesar 12 responden $(48,0 \%)$.

4) Kadar timbal $(\mathrm{Pb})$ darah responden

Berdasarkan kadar $\mathrm{Pb}$ darah dapat dilihat pada tabel 7 berikut.

Tabel 5. Distribusi responden berdasarkan kadar Pb darah operator SPBU di Kota Yogyakarta tahun 2010

\begin{tabular}{ccc}
\hline Kadar Pb darah & Frekuensi & Presentase (\%) \\
\hline tinggi & 14 & 56.0 \\
\hline rendah & 11 & 44.0 \\
\hline Total & 25 & 100.0 \\
\hline
\end{tabular}

Pada tabel 5. di atas menunjukkan bahwa dari 25 responden yang diteliti kebanyakan memiliki kadar $\mathrm{Pb}$ darah tinggi yaitu sebesar 14 responden $(56,0 \%)$, sedangkan yang memiliki kadar $\mathrm{Pb}$ darah rendah sebesar 11 responden (44\%).

4) Hubungan antara kadar $\mathrm{Pb}$ dalam darah dengan kejadian hipertensi pada operator SPBU di Kota Yogyakarta

Tabel 6. Hubungan kadar $\mathrm{Pb}$ darah dengan kejadian hipertensi operator SPBU di Kota Yogyakarta tahun 2010

\begin{tabular}{|c|c|c|c|c|c|c|c|c|}
\hline \multirow{3}{*}{ Kadar $\mathrm{Pb}$ darah } & \multicolumn{6}{|c|}{ Kejadian hipertensi } & \multirow{3}{*}{$P$ value } & \multirow{3}{*}{$R R(95 \% \mathrm{Cl})$} \\
\hline & \multicolumn{2}{|c|}{ Ya } & \multicolumn{2}{|c|}{ Tidak } & \multicolumn{2}{|c|}{ Total } & & \\
\hline & $n$ & $\%$ & $\mathrm{n}$ & $\%$ & $\mathrm{n}$ & $\%$ & & \\
\hline Tinggi & 10 & 40 & 4 & 16 & 14 & 56 & \multirow{3}{*}{0,028} & \multirow{3}{*}{$\begin{array}{c}2,619 \\
(0,944-7,625\end{array}$} \\
\hline Rendah & 3 & 12 & 8 & 32 & 11 & 44 & & \\
\hline Total & 13 & 52 & 12 & 48 & 25 & 100 & & \\
\hline
\end{tabular}

Hubungan hipertensi dengan kejadian hipertensi dapat dilihat pada tabel 8. Hasil penelitian didapatkan bahwa 14 responden (56\%) yang memiliki kadar $\mathrm{Pb}$ darah tinggi, terdapat 10 responden (40\%) yang menderita hipertensi, sedangkan dari 11 responden (44\%) yang memiliki kadar $\mathrm{Pb}$ darah rendah, terdapat 3 responden $(12 \%)$ yang menderita hipertensi. Dari hasil tersebut secara 
persentase, responden yang memiliki kadar $\mathrm{Pb}$ tinggi lebih banyak menderita hipertensi dibandingkan dengan responden yang memiliki kadar $\mathrm{Pb}$ darah rendah.

\section{b. Pembahasan}

Berdasarkan hasil penelitian yang dilakukan pada 25 responden didapatkan responden yang menderita hipertensi sebesar sebesar 13 responden (57\%), sedangkan yang tidak menderita hipertensi sebesar 12 responden (48\%). Hasil ini menunjukkan kejadian hipertensi pada operator SPBU di Kota Yogyakarta masih cukup tinggi. Adapun faktor risiko yang diteliti dalam penelitian ini adalah kadar $\mathrm{Pb}$ dalam darah.

Hasil uji statistik Hubungan kadar $\mathrm{Pb}$ darah dengan kejadian hipertensi dapat dilihat pada tabel 8 . Hasil penelitian didapatkan bahwa 14 responden (56\%) yang memiliki kadar $\mathrm{Pb}$ dalam darah tinggi, terdapat 10 responden $(40 \%)$ yang menderita hipertensi, didapatkan nilai $p=0,028$ lebih kecil dari $\alpha=0,05$, berarti dapat disimpulkan ada hubungan yang signifikan antara kadar $\mathrm{Pb}$ dalam darah dengan kejadian hipertensi. Rata-rata Pb darah petugas operator SPBU sekitar $24,97 \mu \mathrm{g} / \mathrm{dl}$ meskipun kadarnya lebih rendah bila dibandingkan dengan batas kadar aman $\mathrm{Pb}$ dalam darah oleh WHO (1977) sekitar 10-25 $\mu \mathrm{g} / \mathrm{dl}$. Namun nilai tersebut menunjukkan bahwa rata-rata responden telah mengalami keracunan timbal dalam darah karena kadarnya telah melebihi batas keracunan yaitu $5 \mu \mathrm{g} / \mathrm{dll}{ }^{4}$

Dari 11 responden yang memiliki kadar $\mathrm{Pb}$ rendah dalam darah terdapat 3 $(12 \%)$ yang menderita hipertesi, hal ini dapat disebabkan karena kebiasaan responden mengkonsumsi natrium berlebih, merokok, ataupun responden sedang memiliki masalah lainnya yang membuatnya stres sehingga mempengaruhi kerja jantung, pembuluh darah dan system saraf simpati. Sedangkan bagi responden yang memiliki kadar $\mathrm{Pb}$ tinggi dalam darah namun tidak menderita hipertensi dapat diakibatkan karena masa kerja yang dimiliki masih tidak terlalu lama, memiliki hygiene personal yang baik seperti responden menggunakan pakaian seragam kerja lengan pajang pada waktu bekerja, mencuci tangan sebelum makan pada saat setelah bekerja, dan juga mengganti pakaian kerja yang telah terpapar $\mathrm{Pb}$ setelah bekerja sehingga partikel-partikel $\mathrm{Pb}$ yang menempel pada pakaian tidak masuk kedalam tubuh responden baik melalui inhalasi maupun kulit responden tersebut.

Adapun besarnya risiko dapat dilihat dari nilai $\mathrm{RR}=2,619$ (95\% Cl:0,944$7,625)$ artinya responden yang memiliki kadar $\mathrm{Pb}$ tinggi dalam darah mempunyai peluang risiko menderita hipertensi 2,619 kali lebih besar bila dibandingkan dengan responden yang memiliki kadar $\mathrm{Pb}$ rendah dalam darah dan secara statistik bermakna. Hasil ini sesuai dengan pernyataan Lippmann bahwa timbulnya efek terhadap tekanan darah terjadi pada kadar $\mathrm{Pb}$ dalam darah antara $5-35 \mu \mathrm{g} / \mathrm{dl} .{ }^{8}$ Penelitian Riyadina et al. (2002), yang menyatakan bahwa kadar Pb dalam darah tinggi memiliki hubungan dengan kejadian hipertensi. ${ }^{4}$

Adanya keracunan timbal dalam darah responden, kemungkinan diakibatkan karena petugas SPBU bekarja sehari-hari terpapar oleh uap ataupun percikan bensin pada saat mengisi bahan bakar, serta melalui asap kendaraan bermotor yang sedang mengantri untuk mengisi bahan bakar, yang melintasi jalan raya, ataupun kendaraan yang berangkat setelah mengisi bahan bakar. Dan rata-rata masa kerja responden yang panjang yaitu sekitar 4 tahun, hal ini menunjukkan 
bahwa paparan timbal terhadap responden sudah berlangsung lama, sehingga akumulasi timbal dalam tubuh akan semakin tinggi.

Dari hasil pengamatan bahwa seluruh responden tidak menggunakan masker sebagai alat pelindung diri (APD) seperti masker dan sarung tangan. Mereka beralasan karena responden tidak tahu dan tidak pernah disuruh untuk menggunakan APD dan memang seluruh SPBU tidak menyediakan atau memberi saran untuk menggunakan APD kepada operator SPBU. Selain itu, juga disebab karena pihak manajer tidak pernah melakukan pemeriksaan kesehatan awal dan berkala secara rutin bagi para pekerjanya guna mengontrol serta mencegah dampak yang dapat ditimbulkan timbal terhadap kesehatan pekerja.

\section{SIMPULAN DAN SARAN}

\section{a. Simpulan}

Berdasarkan analisa hasil penelitian dan pembahsan pada pada penelitian ini maka dapat disimpulkan bahwa:

1) Rata-rata kadar $\mathrm{Pb}$ dalam darah operator SPBU di kota Yogyakarta sebesar $24,97 \mu \mathrm{g} / \mathrm{dl}$.

2) Operator SPBU di Kota Yogyakarta yang menderita hipertensi sebanyak 13 responden $(57 \%)$.

3) Ada hubungan yang bermakna antara kadar timbal dengan kejadian hipertensi pada operator SPBU di Kota Yogyakarta sebesar RR $=2,619 \quad p=0,028$ dan 95\% Cl:0,944-7,625.

\section{b. Saran}

Berdasarkan kesimpulan penelitian, maka peneliti memberikan saran kepada managemen SPBU untuk:

1) Dapat melindungi pekerjanya terhadap bahaya paparan timbal dengan melakukan pemeriksaan kesehatan awal dan berkala secara rutin, paling sedikit satu kali dalam setahun sehingga dapat mengontrol dan mencegah dampak timbal terhadap tubuh pekerja.

2) Menyediakan dan mendukung pekerja menggunakan alat pelindung diri (APD).

3) Bagi penelitian selanjutnya dapat memaparkan dampak negatif yang dapat ditimbulkan oleh $\mathrm{Pb}$ bagi kesehatan manusia pada organ target lainnya seperti pada sistem reproduksi, hematologi maupun sistem urinaria.

\section{DAFTAR PUSTAKA}

1. Riyadina, W., "Pengaruh Pencemaran Pb (Plumbum) Terhadap Kesehatan", Media Litbangkes, VII(3): 29-32.1997

2. Ardyanto, D., "Deteksi Pencemaran Timah Hitam (Pb) Dalam Darah Masyarakat Yang Terpajan Timbal (Plumbum)", Jurnal Kesehatan Lingkungan, 2 (1): 67-76. 2005

3. Sustrani, L., Alam, S., Hadibroto, I., Hipertensi, PT Gramedia Pustaka Utama, Jakarta. 
4. Riyadina, W., M. Notosiswoyo, Anna M. Sirait, L. Tana, 2002, "Hubungan Antara Plumbum $(\mathrm{Pb})$ dalam darah dengan hipertensi pada operator pompa bensin (SPBU)", Buletin Penelitian Kesehatan, 30 (2): 82-88.2006

5. Armilawaty, Amalia H.,Amiruddin R.,Hipertensi dan Faktor Resiko Dalam Kajian Epidemiologi, FKM. UNHAS. Makasar: http:// ridwanamiruddin.wordpress.com/2007/12/08/hipertensi-dan-faktor-risikonya-dalamkajian-epidemiologi/, diakses pada tanggal 9 April 2010. 2007

6. Bustan, M.N., Epidemiologi Penyakit Tidak Menular, Rineka Cipta, Jakarta. 2002

7. Riyadina, W., Faktor-faktor Risiko Hipertensi Pada Operator Pompa Bensin (SPBU) di Jakarta, Media Litbangkes Vol. XII, No. 2: 29-35.2002

8. Anonim, Pencemaran Udara di Kota Jogja Memprihatinkan: www.indomedia.com, diakses pada tanggal 20 April 2010, Yogyakarta. 2007

9. Mukono, H.J., Toksikologi Lingkungan, Airlangga University Press, Surabaya.2005 